\title{
Deep venous thrombosis during tuberculosis cases of 19-year guinean
}

Abdoulaye Camara*, Sana Samoura, Aly Samoura, Koivogui Diara, Doumbouya Mohamed, Barry M Alpha, SOUMAORO M, Barry Ibrahima Sory, Baldé Elhadj Yaya, Mariama Beavogui, Baldé Mamadou Dadhi and Condé Mamady

*Correspondence: mariboudou@gmail.com

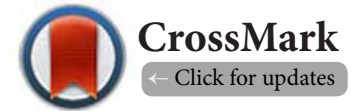

Cardiac Service, Ignace Deen CHU, Conakry, Guinea, West africa.

\begin{abstract}
Observation: This is I S S 19 years admitted pupil for pain of the lower right limb, swelling of the right lower limb, fever and physical asthenia under anti tuberculosis treatment. At the heart: Regular heart sounds at 105bpm, no added noise, blood pressure 110 / 70mmhg. There is a red, feverish swelling in the lower left limb with a positive Homans sign with no detectable entryway. Temperature 38.70c. The rest of the exam is peculiar. Treatment: Lovenox 0.6UI, Sintrom 4mg, Tramadol 50mg.

Conclusion: Tuberculosis is a factor favoring the occurrence of venous thromboembolic disease. Any time the anticoagulant treatment should be started as soon as the signs of MTVE appear preferably heparinotherapy. In the future the scientific world should floor on the interaction Rifampicin and anti vitamin $\mathrm{K}$ in order to find an alternative apart from heparin therapy for the purpose of achieving the therapeutic target whenever tuberculosis is associated with thromboembolic disease.
\end{abstract}

Keywords: Young, Thrombosis, TB

\section{Introduction}

In 2011, 8.7 million new cases were identified by the World Health Organization and TB is responsible for 1.4 million deaths per year [1]. Tuberculosis is considered a risk factor for thromboembolic venous diseases (VTE). The prevalence of this association varies between $0.6 \%$ and $10 \%$ [2]. Some authors have estimated that the actual prevalence of VTE may be greater than $10 \%$ but it is unknown in two-thirds of cases [3].

\section{Observation}

This is I S S 19 years admitted pupil for pain of the right lower limb, swelling of the right lower limb, fever and physical asthenia under anti tuberculosis treatment. At the heart: Regular heart sounds at $105 \mathrm{bpm}$, no added noise, blood pressure 110 / 70mmhg. There is a red, feverish swelling in the lower left limb with a positive Homans sign with no detectable entryway. Temperature 38.70c. The rest of the exam is peculiar. Treatment: lovenox 0.6Ul, Sintrom 4mg, Tramadol 50mg.

\section{Result of the examinations carried out}

Electrocardiogram: normal appearance.

Facial Telethorax: Lung opacities in the cavern located in the right upper lobe.

Venous doppler echo of the lower limbs: shows the presence of an acute deep veinous thrombosis extended from the sural vein extended to the popliteal vein and the superficial femoral vein with thrombus head at the level of the right iliac vein. Biology: THB at $13 \mathrm{~g} / \mathrm{l} ; \mathrm{VS}=50 \mathrm{~mm}$; TP $=49 \%$; $1 \mathrm{st}$ INR $=1.61 ; 2$ nd INR=1.50; Coagulation time $=17$ seconds, negative SRV; Platelet count $=600000 / \mathrm{mm}^{3}$ (Figures 1-4).

\section{Discussion}

We report the case of a young man of 19 years in whom deep vein thrombosis of the lower right limb was diagnosed on pulmonary tuberculosis under anti tuberculosis treatment.

As early as $1856, R$. Virchow described in his triad the mechanisms that can contribute to the formation of a thrombus: the 
Camara et al. Cardiovascular System 2019,

alteration of coagulation, the lesion of the vascular wall and the venous stasis, these 3 mechanisms being often entangled. Tuberculosis acts at these 3 levels. Indeed, during TBC several mechanisms can induce a state of blood hypercoagulability causing thromboembolic complications. Tuberculosis, in its various localizations, can induce in the blood an activation of the mononuclear cells whose interaction with Mycobacterium tuberculosis induces an increased synthesis of the interleukin 6 (IL6), the interleukin 1 and the tumor necrotif alfa factor [4] IL6 stimulates the synthesis of proteins of the acute phase of inflammation including fibrinogen and C4bBP complexing protein $\mathrm{S}$ and factor VIII, which promotes a procoagulant state [6]. Some studies have shown that during the course of tuberculosis the platelet count was increased with not only a decrease in their size, but in addition increase in their aggregability $[7,8,9]$. In our case the platelet count was $600 \mathrm{mil} /$ $\mathrm{mm} 3$. Data from the literature remains controversial regarding the role of rifampicin in the genesis of [10]. Thromboembolic disease Our patient has been on anti-tuberculosis treatment for 2 months and the local signs of deep vein thrombosis have appeared 2 after the start of treatment. The administration of rifampicin is accompanied by a proliferation of the endoplasmic reticulum of the hepatocyte with an enzymatic induction of cytochrome P450, this induction can alter the balance of coagulant and anticoagulant proteins synthesized by the liver thus favoring a state of hypercoagulability [11]. From the therapeutic point of view, although the rifampicin and anti-vitamin $\mathrm{K}$ interaction is well demonstrated, no consensus was established, despite the difficulties encountered in the management of the two associated pathologies. Rifampicin, a bactericidal anti-infective agent used primarily as an antituberculous agent, has a potent cytochrome P450 enzymatic inducing potential. Interactions between rifampicin and antivitamin $\mathrm{K}$ are described, with rifampicin inducing an accelerated catabolism of antis vitamin $\mathrm{K}$ and thus a decrease in the efficacy of oral anticoagulants [12]. For the present case the patient is under acenocoumarol an anti vitamin $\mathrm{K}$ (Sintrom $6 \mathrm{mg}$ per day). Low molecular weight heparins may be a good alternative; but their high cost is a cause of poor compliance of patients with treatment and therefore of stopping it. Due to the high cost of heparin therapy, the patient received only 3 days of heparin therapy of the type Enoxaparin $0.6 \mathrm{IU}$ twice daily. Despite this anticoagulant treatment the therapeutic range that is between 2 and 3 for MVTE has not been reached. Failure to reach the therapeutic target is justified not only by the coagulation effect of tuberculosis but also by the action of rifampicin on the reduction of anticoagulant efficacy of anti-vitamin K. Local signs have completely disappeared within a week. anticoagulant treatment.

\section{Conclusion}

Tuberculosis is a factor that promotes the occurrence of venous thromboembolic disease. Any time the anticoagulant treatment should be started as soon as the signs of MTVE appear preferably heparinotherapy. In the future the scientific world should floor on the interaction Rifampicin and anti vitamin $\mathrm{K}$ in order to find an alternative apart from heparin therapy for the purpose of achieving the therapeutic target whenever tuberculosis is associated with thromboembolic disease.
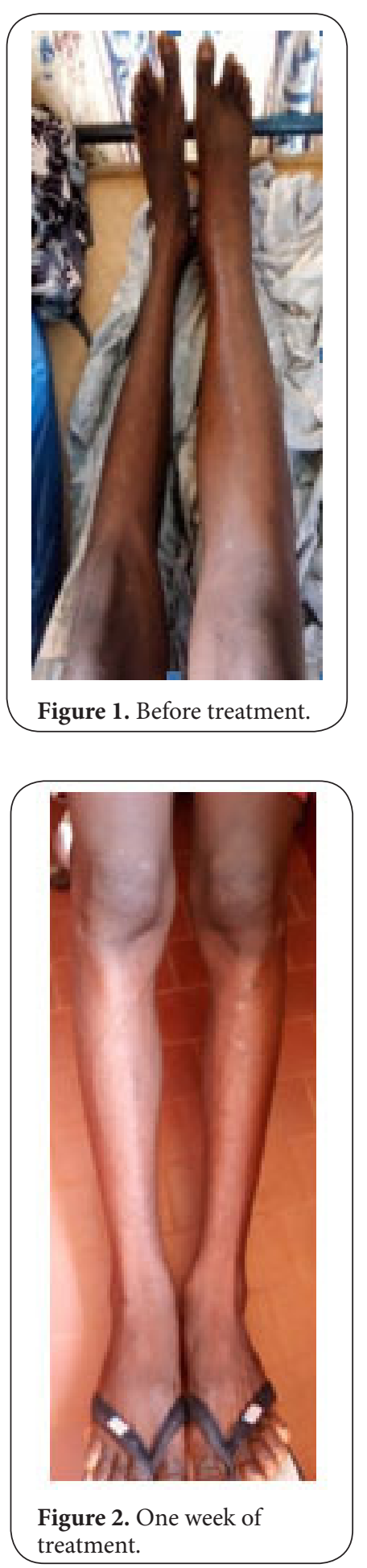


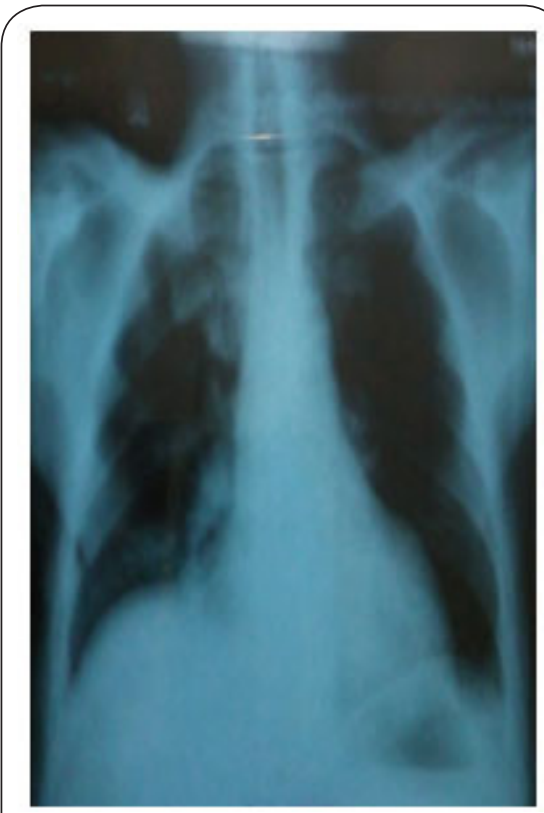

Figure 3. Tele-thorax on the face showing cave opacities located in the right upper lobe.

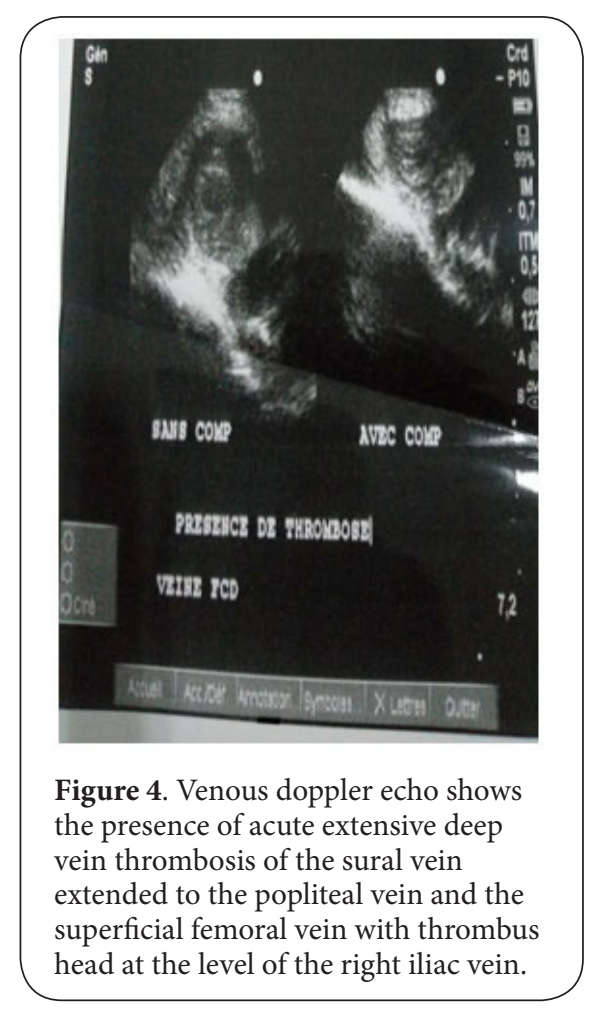

\section{Competing interests}

The authors declare that they have no competing interests.

\section{Publication history}

Editor: Shiwei Duan, Ningbo University, China.

Received: 26-Dec-2018 Final Revised: 16-Feb-2019

Accepted: 19-Feb-2019 Published: 10-Mar-2019

\section{References}

1. Global tuberculosis report 2012. Geneva: World Health Organization. 2012.

2. Malzi I, Arduz E, Alami SM and Marc K. Tuberculosis and thromboembolic disease. Rev Mal Respir. 2012; 29:A115.

3. Anderson FA, Jr., Wheeler HB, Goldberg RJ, Hosmer DW, Forcier A and Patwardhan NA. Physician practices in the prevention of venous thromboembolism. Ann Intern Med. 1991; 115:591-5. | Article | PubMed

4. Turken O, Kunter E, Sezer M, Solmazgul E, Cerrahoglu K, Bozkanat $E$, Ozturk $A$ and Ilvan $A$. Hemostatic changes in active pulmonary tuberculosis. Int J Tuberc Lung Dis. 2002; 6:927-32. | Article I PubMed

5. Abdelkarim $S$. Tuberculous spondylodiscitis complicated by acute ischemia of the lower extremities - about a case. Pan Afr Med J. 2011; 8:45.

6. Buoy F. Cytokines and inflammatory syndrome. In: Galanaud P, Emilie D, editors. Cytokines and internal medicine. Paris: Masson. 1997.

7. Robson SC, White NW, Aronson I, Woollgar R, Goodman H and Jacobs $\mathrm{P}$. Acute-phase response and the hypercoagulable state in pulmonary tuberculosis. Br J Haematol. 1996; 93:943-9. I Article I PubMed

8. Akpan PA, Akpotuzor OJ and Akwiwu EC. Some Africans: the Nigerian perspective. J Natural Sci Res.2012; 2:50-7.

9. Nwankwo EO, Kwaru A, Ofulu A and Babashani M. Haematological changes in tuberculosis in Kano, Nigeria. J Med Lab Sci. 2005; 14:35-9.

10. Raschilas F, Mortar E, Combe A, Grasland A, Pouchot J and Vinceneux P. Rifampicin and venous thrombosis. Rev Med. 2001; 22:485-6.

11. Goncalves IM, Alves DC, Carvalho A, do Ceu Brito M, Calvario F and Duarte R. Tuberculosis and Venous Thromboembolism: a case series. Cases J. 2009; 2:9333. I Article | PubMed Abstract | PubMed FullText

12. Bourguignon L, Golf L, Chatillon F, Bontemps $\mathrm{H}$ and Brantus JF. Interaction between acenocoumarol and rifampicin: presentation of a case and the pharmacokinetic mechanisms involved. J Pharmacie Clin. 2006; 25:105-9.

13. Sharif-Kashani B, Bikdeli B, Moradi A, Tabarsi P, Chitsaz E, Shemirani $\mathrm{S}$, Esmaili-Khansari $\mathrm{M}$ and Masjedi MR. Coexisting venous thromboembolism in patients with tuberculosis. Thromb Res. 2010; 125:478-80. | Article | PubMed

14. El Fekih L, Oueslati I, Hassene $\mathrm{H}$ and Fenniche S. Deep venous thrombosis association with pulmonary tuberculosis. Tunis Med. 2009, 87:328-9.

15. Kwas H, Habibech S, Zendah I, Elmjendel I and Ghedira H. Pulmonary embolism and tuberculosis. Asian Cardiovasc Thorac Ann. 2014; 22:48790. | Article | PubMed

Citation:
Camara A, Samoura S, Samoura A, Diara K, Mohamed
D, Alpha BM, SOUMAORO M, Sory BI, Yaya BE,
Beavogui M, Dadhi BM and Mamady C. Deep venous
thrombosis during tuberculosis cases of 19-year guin-
ean. Cardio Vasc Syst. 2019; 7:1.
http://dx.doi.org/10.7243/2052-4358-7-1

